\title{
MANOSE NA ALIMENTAÇÃO DE LEITÕES NA FASE DE CRECHE (DESEMPENHO, pH DE DO TRATO GASTRINTESTINAL E PESO DOS ÓRGÃOS) ${ }^{1}$
}

\author{
WILAMS GOMES DOS SANTOS ${ }^{2}$ \\ EDUARDO PINTO FILGUEIRAS ${ }^{3}$ \\ ANTÔNIO GILBERTO BERTECHINI ${ }^{3}$ \\ ELIAS TADEU FIALHO ${ }^{3}$ \\ JOSÉ AUGUSTO DE FREITAS LIMA ${ }^{3}$ \\ MARIA APARECIDA VASCONCELOS DE PAIVA BRITO ${ }^{4}$
}

\begin{abstract}
RESUMO - Objetivou-se com o presente trabalho avaliar a utilização de manose como promotor de crescimento em dietas de suínos na fase de creche em alternativa ao uso de antibióticos. Avaliaram-se o desempenho, peso absoluto e relativo do fígado, pâncreas e baço, $\mathrm{pH}$ do conteúdo do estômago e ceco. Foram utilizados 160 leitões desmamados aos 21 dias de idade, sendo 80 machos castrados e 80 fêmeas, com peso médio de $6,2 \mathrm{~kg}( \pm 0,986 \mathrm{~kg})$, em delineamento experimental em blocos ao acaso com cinco tratamentos, oito blocos e quatro leitões por unidade experimental. Os tratamentos consistiram de cinco rações, sendo uma com 25 ppm do antibiótico colistina (controle) e quatro rações
\end{abstract}

com níveis crescentes de manose $(0 \% ; 0,02 \% ; 0,10 \%$; e $0,20 \%$ ). As rações foram isonutrientes com $20 \%$ de PB e $3500 \mathrm{kcal}$ de ED/kg de ração e foram formuladas para atender às exigências dos leitões nessa fase. Observouse que os tratamentos não influenciaram $(\mathrm{P}>0,05)$ o ganho de peso, consumo de ração, conversão alimentar e pH do conteúdo do estômago e do ceco, o mesmo ocorrendo com o peso absoluto e relativo do fígado, pâncreas e baço. Conclui-se que a inclusão de manose como promotor de crescimento às rações de leitões na fase de creche não melhorou o desempenho e não influenciou o peso dos órgãos e o pH do conteúdo do estômago e do ceco.

TERMOS PARA INDEXAÇÃO: Antibiótico, desempenho, leitões, pH, prebiótico, órgãos.

\section{MANNOSE IN PIGLETS FEEDING IN THE NURSERY PHASE: (PERFORMANCE, pH OF THE GASTROINTESTINAL AND WEIGHT OF THE ORGAN)}

\begin{abstract}
The present work was designed to evaluate the use of mannose as a growth-promoting additive for swine in nursery phase as an alternative to the use of antibiotics. The performance, relative weight of the liver, pancreas and spleen, $\mathrm{pH}$ of the stomach and cecum contents were evaluated. A hundred sixty (160) weaned piglets were utilized at 21 days old, 80 being castrated males and 80 females, weighing, on average, $6.2 \mathrm{~kg}( \pm 0.986 \mathrm{~kg})$ in an experimental randomized block design with five replicates, eight blocks and four piglets per experimental unit. The treatments consisted of five rations, one of the rations containing $25 \mathrm{ppm}$ of the antibiotic colistin (control)
\end{abstract}

and four rations with growing levels of mannose $(0 \%$; $0.02 \% ; 0.10 \%$ and $0.20 \%$ ). The diets were isonutrient with $20 \%$ of $\mathrm{CP}$ and $3.500 \mathrm{kcal}$ of $\mathrm{DE} / \mathrm{kg}$ of ration, they were formulated to meet the piglets' requirements in this phase. It was found that the treatments did not influence $(\mathrm{P}>0.05)$ gain weight, feed intake and feed conversion and $\mathrm{pH}$ of the stomach and cecum content. The same occurring with the absolute and relative weight of the liver, pancreas and spleen. It follows that the inclusion of mannose as a growth-promoting additive to the piglet diets in the nursery phase did not improve performance and did not influence the weight of the organs and $\mathrm{pH}$ of the stomach and cecum contents.

INDEX TERMS: Antibiotic, organ, performance, $\mathrm{pH}$, piglets, prebiotic.

\footnotetext{
1. Parte da dissertação apresentada pelo primeiro autor à UNIVERSIDADE FEDERAL DE LAVRAS/UFLA - Caixa Postal 37 - 37200-000 - Lavras, MG.

2. Zootecnista, Mestre em Zootecnia, Bolsista da CAPES.

3. Professores do Departamento de Zootecnia/UFLA.

4. Pesquisadora do CNPGL - EMBRAPA, Juiz de Fora, MG.
} 


\section{INTRODUÇÃO}

O período de creche é considerado uma fase crítica na produção de suínos devido aos vários fatores estressantes que ocorrem simultaneamente por ocasião do desmame, principalmente relacionados com a separação dos leitões da matriz, mudança de ambiente e mudança brusca na alimentação. Conseqüentemente, alguns problemas sanitários como diarréia pós-desmame e doença do edema podem surgir, ocasionando perdas econômicas pela elevação da taxa de mortalidade e pela redução no ganho de peso dos leitões. Na tentativa de controlar tais problemas, o uso de antibióticos em níveis subterapêuticos tornou-se, por muitas décadas, prática rotineira no desenvolvimento de estratégias nutricionais. Por outro lado, existe uma pressão crescente para proibir o uso dos antibióticos promotores de crescimento. A razão para essa proibição está principalmente baseada na resistência de cepas bacterianas patogênicas. Diante dessa situação, a proibição dos antibióticos promotores de crescimento transformou-se em um grande desafio e a busca por alternativas é a pauta mais atual entre os pesquisadores. Uma das alternativas é o uso de prebióticos, açúcares que são adicionados às rações como aditivos e que agem alimentando e estimulando o crescimento de diversas bactérias intestinais. Por outro lado, atuam bloqueando os sítios de aderência (principalmente a Dmanose e derivados) de algumas bactérias. Uma das vantagens dos prebióticos em relação aos antibióticos promotores de crescimento é a ausência do fenômeno da resistência bacteriana. Diante de tais fatos, com o presente trabalho, objetivou-se, verificar o efeito da adição de manose, como prebiótico (Cocco-Ace ${ }^{\circledR}$ ), às dietas de leitões durante a fase de creche sobre o desempenho, $\mathrm{pH}$ do estômago, ceco e peso do fígado, pâncreas e baço.

\section{MATERIAL E MÉTODOS}

O experimento foi conduzido de fevereiro a maio de 2001, no Setor de Suinocultura do DZO da UFLA. Foram utilizados 160 leitões mestiços, sendo 80 machos e 80 fêmeas, desmamados aos 21 dias de idade, com peso médio de $6,2 \mathrm{~kg}( \pm 0,986 \mathrm{~kg})$. Os animais foram alojados no galpão de creche, em baias suspensas $(2,00 \times 1,20$ $\mathrm{m})$, com piso totalmente ripado, equipadas com comedouros semi-automáticos e bebedouros tipo chupeta. As dietas experimentais foram formuladas de forma a atender as exigências nutricionais dos leitões durante o período de creche (21 aos 60 dias de idade), segundo Rostagno et al. (2000). As dietas, na forma farelada, foram formuladas à base de milho e farelo de soja, suplementadas com minerais e vitaminas, com os mesmos níveis de nutrientes. A composição química dos ingredientes e a composição percentual da dieta basal encontram-se nas Tabelas 1 e 2, respectivamente. Os leitões foram submetidos a cinco dietas experimentais, sendo quatro níveis de manose $(0,0 \% ; 0,02 \%$; $0,1 \%$ e $0,2 \%)$ e uma dieta-controle com antibiótico promotor do crescimento (25 ppm de Colistina).

TABELA 1 - Composição bromatológica dos ingredientes usados nas rações.

\begin{tabular}{|c|c|c|c|c|c|c|}
\hline \multirow[b]{2}{*}{ Composição ${ }^{1}$} & \multicolumn{6}{|c|}{ Ingredientes } \\
\hline & Milho & Açúcar & $\begin{array}{c}\text { Óleo de } \\
\text { Soja }\end{array}$ & $\begin{array}{c}\text { Farelo de } \\
\text { Soja }\end{array}$ & $\begin{array}{c}\text { Fosfato } \\
\text { Bicálcico }\end{array}$ & Calcário \\
\hline Matéria seca $(\%)^{2}$ & 86,30 & 99,86 & 99,30 & 88,20 & - & - \\
\hline Proteína bruta $(\%)^{2}$ & 7,81 & 0,09 & - & 46,10 & - & - \\
\hline E.D. $(\mathrm{kcal} / \mathrm{kg})^{3}$ & 3476 & 3958 & 8469 & 3421 & - & - \\
\hline Cálcio $(\%)^{2}$ & 0,03 & - & - & 0,32 & 26,86 & 38,48 \\
\hline Fósforo disponível $(\%)^{2}$ & 0,08 & - & - & 0,19 & 20,31 & - \\
\hline Lisina $(\%)^{3}$ & 0,25 & - & - & 2,78 & - & - \\
\hline Metionina + cistina $(\%)^{3}$ & 0,37 & - & - & 1,27 & - & - \\
\hline
\end{tabular}

Ciênc. agrotec., Lavras. V.27, n.3, p.696-702, maio/jun., 2003 
Para o desempenho, foram avaliados o ganho de peso médio diário (GPMD), consumo de ração médio diário (CRMD) e a conversão alimentar (CA). Para determinação do ganho de peso, os animais foram pesados aos 21 e aos 60 dias de idade. As rações e o desperdício foram pesados para determinação do consumo. A conversão alimentar foi obtida por meio da relação entre o consumo de ração e o ganho de peso durante o período experimental.

Para peso dos órgãos e pH do conteúdo do estômago e ceco, foi abatido um animal por parcela, totalizando 40 animais, sendo escolhido aquele com peso mais próximo da média da parcela experimental. Imediatamente, as vísceras foram expostas por uma incisão mediana e as seções do trato gastrintestinal foram assepticamente isoladas com dupla ligadura. Em seguida, foi medido o $\mathrm{pH}$ do conteúdo da porção distal do estômago e do ceco. Também foi efetuada a retirada de órgãos (fígado, pâncreas e baço) para determinar o peso absoluto e relativo dos mesmos. O delineamento utilizado foi em blocos casualizados (DBC), utilizando-se cinco tratamentos com oito blocos. Cada unidade experimental foi composta por quatro leitões, sendo dois machos (castrados) e duas fêmeas alojados em baias coletivas, totalizando 32 leitões por tratamento. Os blocos foram constituídos para controlar as diferenças inicias de peso. As análises estatísticas foram realizadas segundo pacote estatístico SISVAR, descrito por Ferreira (2000), e as médias dos tratamentos foram comparadas pelo teste de StudentNeuman-Keuls a 5\% de probabilidade.

\section{RESULTADO E DISCUSSÃO}

Os resultados de desempenho para as variáveis consumo de ração médio diário (CRMD), ganho de peso médio diário (GPMD) e conversão alimentar (CA) encontram-se na Tabela 3.

Pelos resultados, verificou-se que não houve influência dos tratamentos no consumo de ração médio diário, ganho de peso médio diário e conversão alimen$\operatorname{tar}(\mathrm{P}>0,05)$. Esse comportamento foi também observado por Stockland (1999), quando utilizou 0,10\% de oligossacarídeo de manose adicionado às dietas de leitões desmamados.

Dvorak \& Jacques (1998) e Brendemuhl \& Harvey (1999), utilizando $0,20 \%$ de oligossacarídeo de manose adicionados às dietas de leitões desmamados aos 17 e 21 dias de idade, respectivamente, também não encontraram diferenças significativas no desempenho. Em contraste, Davis et al. (1999) encontraram diferen- ças significativas no ganho de peso médio diário e conversão alimentar, quando utilizaram $0,20 \%$ do mesmo prebiótico na alimentação de leitões desmamados aos 21 dias de idade.

Os resultados para as variáveis peso absoluto e relativo do fígado, pâncreas e baço dos leitões encontram-se nas Tabelas 4 e 5.

Os pesos absoluto e relativo do fígado e pâncreas não foram influenciados $(\mathrm{P}>0,05)$ pelos tratamentos. Segundo Rao \& McCracken (1992), os pesos dos órgãos variam com o consumo de energia e/ou proteína, sugerindo que mantidas as mesmas quantidades, os pesos serão semelhantes.

Provavelmente, um dos efeitos mais importantes da manose é sua capacidade de alterar a função do sistema imunológico dos animais. Segundo Dawson \& Pirvulescu (1999), diversos conjuntos de evidências indicam que a adição de prebiótico de manose às dietas de animais pode estimular a função de defesa imunológica. Apesar desse efeito, ao se avaliar o peso absoluto e relativo do baço, constatou-se que não foram influenciados $(\mathrm{P}>0,05)$ pelos tratamentos.

As medidas relativas ao $\mathrm{pH}$ do conteúdo do estômago e ceco dos leitões encontram-se na Tabela 6 .

Os valores de $\mathrm{pH}$ do conteúdo do estômago e do ceco não foram influenciados $(\mathrm{P}>0,05)$ pelos tratamentos, embora tenham sido levemente mais ácidos para o nível de $0,1 \%$ de manose, em relação aos demais.

$\mathrm{O}$ pH do conteúdo do trato gastrintestinal tende a aumentar ao longo do seu comprimento, chegando a neutro no reto (Adams, 2000). Os valores de $\mathrm{pH}$ do conteúdo do estômago estão de acordo com Jonsson \& Conway (1992), que verificaram uma amplitude de 2,3 a 4,5. Entretanto, os valores de $\mathrm{pH}$ do conteúdo do ceco estão abaixo de 7,40 e 6,02 encontrados por Vervaeke et al. (1973) e Allison et al. (1979), respectivamente. Têm-se verificado em vários estudos resultados controversos de medidas do $\mathrm{pH}$ do conteúdo do estômago, devido a uma série de fatores: a região onde foram feitas as determinações, o tipo de técnica usada, o tempo após a ingestão de alimento, entre outros (Ferreira, 1986).

O abaixamento do $\mathrm{pH}$ é importante para diminuir o crescimento de bactérias patogênicas, como Escherichia coli e Salmonella, pois elas não são capazes de sobreviverem em $\mathrm{pH}$ ácido, ao contrário das bactérias não-patogênicas. Neste experimento, observou-se que a faixa de $\mathrm{pH}$ do conteúdo de estômago encontrou-se abaixo do mínimo exigido para o crescimento da $E$. coli 
e Salmonella. No ceco, observaram-se valores de $\mathrm{pH}$ dentro da faixa ótima para crescimento de lactobacilus. Blanchard (2000) verificou que a faixa ótima para cres- cimento da E. coli está entre 4,3 e 9,5; para Salmonella sp, está entre 4,0 e 9,0 e para Lactobacillus sp, entre 3,8 a 7,2 .

TABELA 2 - Composição percentual e bromatológica das rações experimentais.

\begin{tabular}{|c|c|c|c|c|c|}
\hline \multirow{2}{*}{ Ingrediente } & \multicolumn{5}{|c|}{ Nível de manose (\%) } \\
\hline & Controle & $\mathbf{0}$ & $\mathbf{0 , 0 2}$ & $\mathbf{0 , 1}$ & 0,2 \\
\hline Milho & 58,007 & 58,007 & 58,007 & 58,007 & 58,007 \\
\hline Farelo de soja & 31,569 & 31,569 & 31,569 & 31,569 & 31,569 \\
\hline Açúcar & 3,029 & 3,029 & 3,029 & 3,029 & 3,029 \\
\hline Óleo de Soja & 2,966 & 2,966 & 2,966 & 2,966 & 2,966 \\
\hline Fosfato Bicálcico & 2,128 & 2,128 & 2,128 & 2,128 & 2,128 \\
\hline Calcário & 0,661 & 0,661 & 0,661 & 0,661 & 0,661 \\
\hline Sal Iodado & 0,456 & 0,456 & 0,456 & 0,456 & 0,456 \\
\hline Lisina - HCL - 99\% & 0,430 & 0,430 & 0,430 & 0,430 & 0,430 \\
\hline Caulim & 0,1975 & 0,200 & 0,180 & 0,10 & - \\
\hline DL-Metionina - 99\% & 0,196 & 0,196 & 0,196 & 0,196 & 0,196 \\
\hline L-Treonina - 98\% & 0,158 & 0,158 & 0,158 & 0,158 & 0,158 \\
\hline Colistina & 0,0025 & - & - & - & - \\
\hline Manose & - & - & 0,020 & 0,100 & 0,200 \\
\hline Premix Vitamínico $^{1}$ & 0,100 & 0,100 & 0,100 & 0,100 & 0,100 \\
\hline Premix Mineral $^{2}$ & 0,100 & 0,100 & 0,100 & 0,100 & 0,100 \\
\hline TOTAL & 100 & 100 & 100 & 100 & 100 \\
\hline \multicolumn{6}{|c|}{ Nível Nutricional Calculado } \\
\hline Proteína bruta (\%) & 20,00 & 20,00 & 20,00 & 20,00 & 20,00 \\
\hline $\mathrm{ED}(\mathrm{kcal} / \mathrm{kg})$ & 3500 & 3500 & 3500 & 3500 & 3500 \\
\hline $\mathrm{Ca}(\%)$ & 0,900 & 0,900 & 0,900 & 0,900 & 0,900 \\
\hline Fósforo Disponível (\%) & 0,500 & 0,500 & 0,500 & 0,500 & 0,500 \\
\hline Lisina $(\%)$ & 1,360 & 1,360 & 1,360 & 1,360 & 1,360 \\
\hline Metionina +Cistina (\%) & 0,810 & 0,810 & 0,810 & 0,810 & 0,810 \\
\hline
\end{tabular}

1'-Vit. A (8.000.000 UI); Vit. D (1.200.000 UI); Vit. E (20.000mg); Vit K3 (2500mg); Tiamina (1000mg); Riboflavina (4000mg); Vit $\mathrm{B}_{12}(20 \mathrm{mg})$, Niacina $(25000 \mathrm{mg})$; Ácido Pantotênico (10.000mg); Biotina (50g); Ácido Fólico (600mg); Vit. C (50.000 mg), Antioxidante (125mg).

² Zn (80000mg); Fe (70000mg); Mn (40000mg); Cu (20000mg), I (800mg); Co (500mg); Se (500mg), Veículo qsp (1000g). 
TABELA 3 - Consumo de ração médio diário (CRMD), ganho de peso médio diário (GPMD) e conversão alimentar (CA) de leitões dos 21 aos 60 dias de idade, de acordo com os níveis de manose adicionados às dietas ${ }^{1}$.

\begin{tabular}{cccc}
\hline Tratamento & CRMD $(\mathbf{k g})$ & GPMD $(\mathbf{k g})$ & CA \\
\hline Controle & $\mathbf{0 , 4 5 9}$ & $\mathbf{0 , 2 6 3}$ & $\mathbf{1 , 7 4}$ \\
\hline Nível de manose & & & \\
$0 \%$ & 0,489 & 0,296 & 1,65 \\
$0,02 \%$ & 0,484 & 0,279 & 1,73 \\
$0,1 \%$ & 0,422 & 0,269 & 1,57 \\
$0,2 \%$ & 0,471 & 0,297 & 1,59 \\
\hline C.V. $(\%)$ & 13,77 & 17,33 & 11,66 \\
\hline
\end{tabular}

${ }^{1}$ Não houve diferença significativa $(\mathbf{P}>0,05)$

TABELA 4 - Peso absoluto (kg) do fígado, pâncreas e baço de leitões dos 21 aos 60 dias de idade, de acordo com os níveis de manose adicionados às dietas ${ }^{1}$.

\begin{tabular}{cccc}
\hline Tratamento & Fígado & Pâncreas & Baço \\
\hline Controle & $\mathbf{0 , 5 0 6}$ & $\mathbf{0 , 0 3 7}$ & $\mathbf{0 , 0 2 9}$ \\
\hline Nível de manose & & & \\
$0 \%$ & 0,569 & 0,041 & 0,027 \\
$0,02 \%$ & 0,580 & 0,039 & 0,032 \\
$0,1 \%$ & 0,573 & 0,036 & 0,030 \\
$0,2 \%$ & 0,587 & 0,041 & 0,031 \\
\hline C.V. $(\%)$ & 16,27 & 25,77 & 29,17 \\
\hline
\end{tabular}

${ }^{1}$ Não houve diferença significativa $(\mathbf{P}>\mathbf{0 , 0 5})$.

TABELA 5 - Peso relativo (\%) do fígado, pâncreas e baço de leitões dos 21 aos 60 dias de idade, de acordo com os níveis de manose adicionados às dietas ${ }^{1}$.

\begin{tabular}{cccc}
\hline Tratamento & Fígado & Pâncreas & Baço \\
\hline Controle & $\mathbf{3 , 3 0}$ & $\mathbf{0 , 2 4}$ & $\mathbf{0 , 1 8}$ \\
\hline Nível de manose & & & \\
$0 \%$ & 3,23 & 0,23 & 0,15 \\
$0,02 \%$ & 3,27 & 0,22 & 0,18 \\
$0,1 \%$ & 3,27 & 0,20 & 0,17 \\
$0,2 \%$ & 3,28 & 0,23 & 0,18 \\
\hline C.V. (\%) & 12,56 & 20,28 & 21,75 \\
\hline
\end{tabular}

${ }^{1}$ Não houve diferença significativa $(\mathbf{P}>\mathbf{0 , 0 5})$

Ciênc. agrotec., Lavras. V.27, n.3, p.696-702, maio/jun., 2003 
TABELA 6 - Medidas relativas ao pH do conteúdo do estômago e do ceco de leitões dos 21 aos 60 dias de idade, de acordo com os níveis de manose adicionados às dietas ${ }^{1}$.

\begin{tabular}{ccc}
\hline Tratamento & Estômago & Ceco \\
\hline Controle & $\mathbf{3 , 4 0}$ & $\mathbf{5 , 4 3}$ \\
\hline Nível de manose & & \\
$0 \%$ & 3,53 & 5,32 \\
$0,02 \%$ & 3,84 & 5,33 \\
$0,1 \%$ & 3,33 & 5,29 \\
$0,2 \%$ & 3,75 & 5,42 \\
\hline C.V. $(\%)$ & 13,02 & 4,14 \\
\hline
\end{tabular}

${ }^{1}$ Não houve diferença significativa $(\mathbf{P}>\mathbf{0 , 0 5})$

\section{CONCLUSÕES}

A inclusão de manose às dietas para leitões em fase de creche como promotor de crescimento não melhorou o desempenho e não influenciou o peso dos órgãos e o pH do conteúdo do estômago e do ceco, o mesmo ocorreu com a dieta com inclusão de antibiótico.

\section{REFERÊNCIAS BIBLIOGRÁFICAS}

ADAMS, A. C. Acidifiers: important components of pig feeds. Technical Information, Singapore, p. 1-6, 2000 .

ALLISON, M. J.; ROBINSON, I. M.; BUCKLIN, J. A.; BOOTH, G. D. Comparison of bacterial populations of the pig caecum and colon based upon enumeration with specific energy sources. Applied and Environmental Microbiology, Washington, v. 37, p. 1142-1151, 1979.

BLANCHARD, P. Less buffering, more enzymes and organic acids. [S.1.]: Feed Mix, 2000.

BRENDEMUHL, J. H.; HARVEY, M. R. Evaluation of Bio-Mos (mannanoligosaccharide) in diets for pigs: I growth performance response during nursery and growing-finishing phases. Florida: University of Florida, 1999.

DAVIS, M. E.; MAXWUELL, C. V.; KEGLEY, B. Z. de R.; FRIESEN, K. G.; HELLWIG, D. H.;
DVORAK, R. A. Efficacy of mannan oligosaccharide (Bio-Mos) addition at two levels of supplemental copper on performance and immunocompetence of early weaned pigs. Journal of Animal Science, Champaign, v. 77, p. 6, 1999. Abstract.

DAWSON, K. A.; PIRVULESCU, M. Mananoligossacarídeos derivados de leveduras como moduladores da resposta imunológica e alternativas aos promotores de crescimento antimicrobianos. In: RONDA LATINO-AMERICANA DA ALLTECH, 9., 1999, Curitiba. Anais... Curitiba: [s.n.], 1999. p. 33-41.

DVORAK, R.; JACQUES, K. A. Mannanoligosaccharide, frutoligosaccharide and carbadox for pigs days 0 21 post-weaning. Journal of Animal Science, Champaign v. 76, p. 64, 1998. Abstract.

FERREIRA, A. S. Estimativa de produção e composição de leite de porca e aleitamento artificial de leitões. 1986. 121 f. Tese (Doutorado em Nutrição de Monogástrico) - Universidade Federal de Viçosa,Viçosa.

FERREIRA, D. F. Análises estatísticas por meio do Sisvar para Windows versão 4.0. In: REUNIÃO ANUAL DA REGIÃO BRASILEIRA DA SOCIEDADE INTERNACIONAL DE BIOMETRIA, 45., 2000, São Carlos. Anais... São Carlos: UFSCAR, 2000. p. 255-258. 
JONSSON, E.; CONWAY, P. Probiotics for pigs. In: FULLER, R. Probiotics: the scientific basis. London: Chapman and Hall, 1992. p. 259-316.

RAO, D. S.; McCRACKEN, K. J. Energy: protein interactions in growing boars of high genetic potencial for lean growth: I effects on growth, carcass characteristics and organ weights. Animal Production, Edinburgh, v. 54, n. 1, p. 75-82, 1992.

ROSTAGNO, H. S. Tabelas brasileiras para aves e suínos: composição de alimentos e exigências nutricionais. Viçosa: UFV, 2000. 141 p.
STOCKLAND, W. L. Pratical solutions to maximise production: the commercial application of oligosaccharides in starter pig diets. In: ANNUAL TURTLE LAKE PIG SCIENCE CONFERENCE, 1., 1999, Nottingham. Anais... Nottingham: Nottingham University, 1999.

VERVAEKE, I. J.; VAN NEVEL, C. J.; DECUYPERE, J. A.; VAN ASSCHE, P. F. A comparison of two methods for obtaining anaerobic counts in different segments of the gastrointestinal tract of piglets. Journal of Applied Bacteriolgy, Oxford, v. 36, p. 397-405, 1973. 